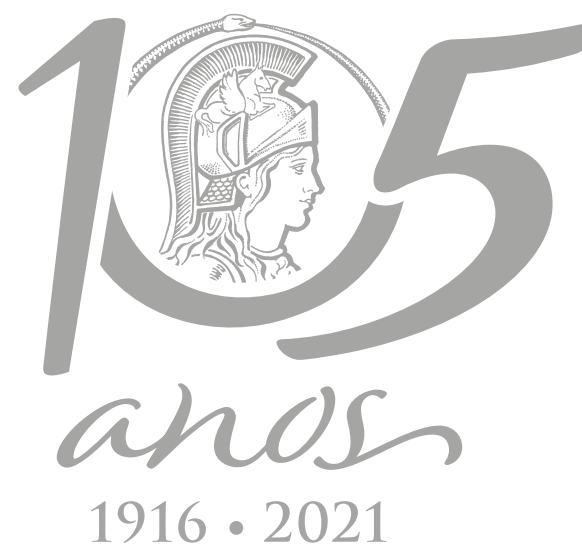

\title{
ECOSYSTEMS
}

\section{Native and non-native species of Litopenaeus Pérez-Farfante, 1969 (Crustacea: Penaeidae) from the East Atlantic: Geometric morphometrics as a tool for taxonomic discrimination}

\author{
ALEX B. DE MORAES, DANIELE C.S. DE MORAES, CARLOS EDUARDO R.D. ALENCAR \\ \& FÚLVIO A.M. FREIRE
}

\begin{abstract}
The shape of the secondary sexual characters is, traditionally, used to discriminate the marine shrimps at the species level. However, the qualitative evaluation of structures that are morphologically variable in the taxonomy of species can favor misunderstandings and misidentifications. These possibilities of taxonomic inaccuracies are especially alarming when there is a need to evaluate the invasion of introduced species. The present study used geometric morphometric analyses to identify differences in the cephalothorax shape that would help discriminate the native and non-native species of Litopenaeus of the South American coast. The comparative morphology analysis was conducted using the right profile of adult males' cephalothorax of L. schmitti, captured in the natural environment, and L. vannamei captured in the natural environment or grown in shrimp farms. In intraspecific evaluation, it was not possible to distinguish the specimens of L. vannamei that were grown in shrimp farms from those acclimated to the natural environment. However, significant interspecific differences in shape were found in the shape of this body structure. Additionally, the base position of the first rostral spine to the tip of the hepatic spine is indicated as a characteristic that can be used to distinguish these two species by eye in the field.
\end{abstract}

Key words: white shrimp, morphological comparison, exotic species, bioinvasion, taxonomy.

\section{INTRODUCTION}

The species identification of many Penaeidae shrimps, within the same genus, is primarily characterized by the shape of the secondary sexual characters, due to their great anatomical diversity between the species and the tremendous morphological conservation of the other characters (Dall et al. 1990, Lavery et al. 2004, Pérez-Farfante \& Kensley 1997). Although these structures are easy to visualize and to distinguish interspecifically, they may be variable within species, since their shape changes along the ontogenetic development (Pérez-Farfante
1970). The use of only one morphological structure, of variable tendency, in the species identification can promote confusion and incorrect identifications. Taxonomic imprecision is especially alarming when there is a need to evaluate introduced species' invasion, but it is difficult to distinguish them from their native counterparts.

In several regions of the world, shrimp Litopenaeus vannamei (Boone, 1931) is one of the most widely used species in the production of cultured marine shrimps (Freitas et al. 2007), due to its characteristics of high adaptation, 
rapid growth, and high survival rates to adverse environmental conditions (Briggs et al. 2004). Originally from the Eastern Pacific, this species is used by shrimp farmers throughout the Western Atlantic (Tavares 2011). Its extensive cultivation facilitated the possibility of escape to the natural environment, allowing individuals to be found co-occurring with their native congener, L. schmitti (Burkenroad, 1936) (Barbieri \& Melo 2006, Loebmann et al. 2010, Santos \& Coelho 2002). Although there are numerous escape cases, the population status of $L$. vannamei in the natural environment in the Atlantic coastline of South America is still uncertain.

In the search for alternatives that increase the accuracy of identifications and aid in discriminating the native and non-native species, new and more resolutive methods are needed to quantitatively describe the body shape of animals, among which geometric morphometric techniques stand out (Rohlf \& Marcus 1993). These techniques have their roots in traditional morphometrics, allowing statistical inference, however, preserving information about the geometry (Adams et al. 2004) of the desired body structure. Besides, it allows the quantification of characteristics that are difficult to measure with traditional techniques.

The presence of rigid body structures in marine shrimps makes it a useful organism for the use of geometric morphometric techniques, especially those based in anatomical landmarks. Since it fulfills the prerequisites and is involved in multiple functions in the shrimps, the cephalothorax is considered a structure not only well recognized for taxonomic distinction but also adequate to investigate morphological responses to contrasting environments (Accioly et al. 2013, Bissaro et al. 2013, Sganga et al. 2016, Zimmerman et al. 2011). Species can show different alterations in the basic structure of the cephalothorax, reflecting signs of sexual dimorphism (Accioly et al. 2013, Alencar et al. 2014, Sganga et al. 2016, Moraes et al. 2020), environmental adaptation (Bissaro et al. 2013, Zimmerman et al. 2011), or as a reflection of genetic differences resulting from selective pressures (Helms et al. 2015).

Species widely cultivated, and present invasion records are of particular interest for monitoring. Such as L. vannamei invasion in South America. Techniques and procedures that allow the identification of specimens captured in the natural environment and distinguishment whether these are coming from accidental releases, or if they are completing their life cycle in the natural environment are thus emergent. Therefore, this study aimed to discriminate between the non-native species Litopenaeus vannamei and the native congener from western Atlantic L. schmitti, with the use of landmark-based geometric morphometrics. Thus, contributing with information that could help correctly assess the population status of these species.

\section{MATERIALS AND METHODS}

Specimens of Litopenaeus schmitti and $L$. vannamei were collected from the natural environment, in the coastal strip of the Baía Formosa municipality (06²1'49,302"S $\left.35^{\circ} 00^{\prime} 36,830^{\prime \prime} \mathrm{W}\right)$, Northeastern Brazil. Samplings were performed monthly, between March of 2013 and February of 2015, using a motorized fishing boat equipped with a single-rig trawl. Additionally, L. vannamei specimens from shrimp farms were obtained by purchasing an equal number of individuals cultivated by three independent producers in the State of Rio Grande do Norte, Northeast of Brazil. Immediately after capture, all animals were cryo anesthetized on ice and subsequently fixed in 95\% ethanol. 
The identification of the specimens was based on Pérez-Farfante $(1969,1988)$, and the sex was determined from the observation of the presence (males) or absence (females) of the adult male sexual character (petasma), located in the first pair of pleopods. In this study, only specimens with intact cephalothorax and rostrum were used. In order to avoid the effects of body shape variation of ontogenetic allometry and sexual dimorphism, only male shrimps from the same adult cohort (animals that were sexually mature morphologically) were used. Morphological sexual maturity was defined by the presence of united and fully developed endopodites (Pérez-Farfante 1969). Thirty specimens of Litopenaeus schmitti, thirteen of $L$. vannamei obtained in the natural environment, and thirty of L. vannamei obtained in shrimp farms were used for morphometric investigation, considering the species or origin of the animals as distinct groups.

All specimens had the right cephalothorax profile (unpaired symmetry; Cardini 2016) photographed by the same researcher (Moraes, A.B.), using a Nikon Coolpix L810 (16.1 megapixels) digital camera, at maximum resolution, coupled to a tripod. The distance from the lens to the body structure, the zoom constancy, and the central position in the picture frame were standardized. Tests of error measurement of photo capture and positioning of landmarks (Viscosi \& Cardini 2011) were performed before the investigations for each species and a group of origin (results not shown).

The Software tpsDig 2.26 (Rohlf 2006) was used for digitizing eight anatomical landmarks selected based on morphometric homology criteria according to the Bookstein's classification (1982). Additionally, 11 anatomical semi-landmarks were digitized in the cephalothorax (Fig. 1, Table I). The semilandmarks were used to represent homologous curves to establish a geometric homology between corresponding semi-landmarks through the samples (Gunz \& Mitteroecker 2013). The coordinates of the semi-landmarks were aligned using the curves tool of Tpsdig 2.26 software (Rohlf 2006) to draw a curve over the edge of the desired structure. Subsequently, a curve resampling was performed to distribute

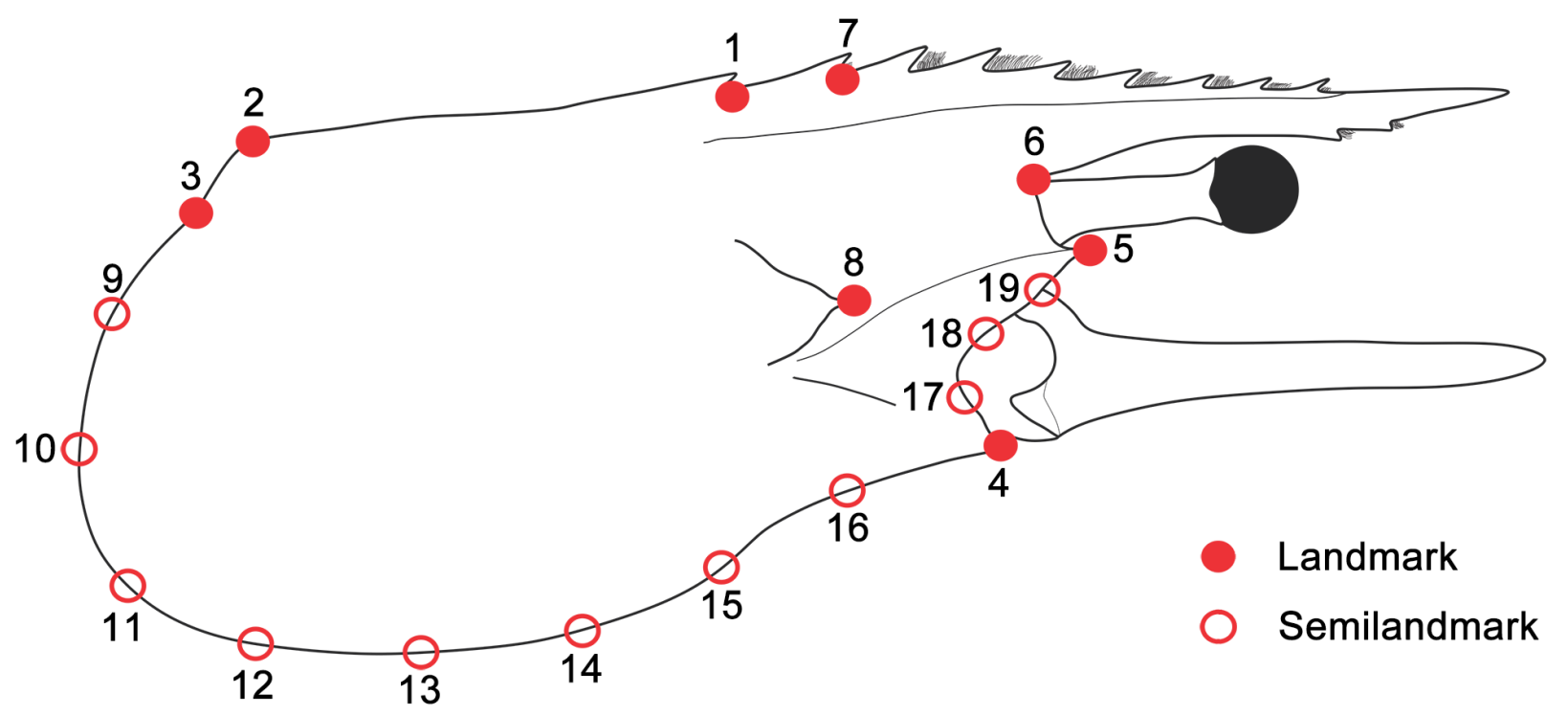

Figure 1. Location of landmarks and semi-landmarks on the cephalothorax right profile for investigation of geometric morphometry. Illustration from Litopenaeus vannamei (Boone, 1931). 
equal numbers of semi-landmarks on the curve using the equidistance criterion. It used eight semi-landmarks for the cephalothorax's posteroventral edge, between the landmarks 3 and 4 , and three semi-landmarks for the anterior border between landmarks 4 and 5. This procedure aims to eliminate arbitrary spacing effects of digitized semi-landmarks in curves.

The coordinates of the landmarks were subjected to a Generalized Superimposition of Procrustes Analysis (GPA) (Rohlf \& Slice 1990) in the software Morphoj $1.06 D^{\circledR}$ (Klingenberg 2011). This technique corrects the effects of scaling, rotation, and positioning of the specimens, maintaining only the shape settings (Adams et al. 2013, Dryden \& Mardia 1998).

Table I. List of landmark descriptions used in the investigation of the variation of the cephalothorax shape of Litopenaeus schmitti (Burkenroad, 1936) and L. vannamei (Boone, 1931).

\begin{tabular}{|c|c|}
\hline Landmark & DESCRIPTION \\
\hline 1 & Anterior base of the epigastric tooth \\
\hline 2 & $\begin{array}{l}\text { Distal point of the posterior dorsal } \\
\text { margin of cephalothorax }\end{array}$ \\
\hline 3 & $\begin{array}{l}\text { Distal point of the posterodorsal } \\
\text { margin of the cephalothorax }\end{array}$ \\
\hline 4 & $\begin{array}{l}\text { Proximal point of the antero-ventral } \\
\text { margin of the cephalothorax }\end{array}$ \\
\hline 5 & Antennal spine tip \\
\hline 6 & Apex of the orbital cavity \\
\hline 7 & $\begin{array}{c}\text { Anterior base of the first tooth of the } \\
\text { rostral spine }\end{array}$ \\
\hline 8 & Hepatic spine tip \\
\hline $9-16$ & $\begin{array}{c}\text { Marginal semi-landmarks of the } \\
\text { posteroventral angle }\end{array}$ \\
\hline $17-19$ & $\begin{array}{l}\text { Semi-landmarks of the margin } \\
\text { between the antennal and } \\
\text { Pterygostomian spines }\end{array}$ \\
\hline
\end{tabular}

A multivariate regression (grouped between species and origin) of the coordinates of Procrustes (shape) on centroid size (size) were used to analyze the variation of shape by the allometric effect (Drake \& Klingenberg 2008). Static or ontogenetic allometric effects (Cock 1966) are not desirable in this study. In order to avoid them, The allometric correction procedure proposed by Alencar et al. (2014) was used to compare the body shape of each species and origin group. For this, the residuals of the multivariate regression were used for the subsequent statistical analyses and evaluations of variation of the shape.

A Canonical Variates Analysis (CVA) was performed using the grouping factors 'species' vs. 'origin of specimens' to investigate the degrees of similarity between body shapes within the morpho-space of all data obtained. Then, a Discriminant Function Analysis (DFA) was applied to evaluate which variations in shape could reliably distinguish the species and, separately, the origin of the specimens. Probability values were computed from the permutation test $(n=10,000)$ based on Procrustes distances in the comparisons performed in CVA and DFA. The values of Procrustes distance were preferred over Mahalanobis distance because the first is the measure of the absolute amount of variation of the shape, while the second is a relative measure of the variation of the shape (Klingenberg \& Monteiro 2005). Finally, we analyze cross-validation matrix percentages obtained in the DFA comparisons.

Procedures of Generalized Superimposition of Procrustes, allometric correction, and multivariate analyses were performed in software MorphoJ $1.06 D^{\circledR}$ (Klingenberg 2011). Transformation grids and comparative wireframe graphs (Klingenberg 2013) were generated from the scores obtained in the DFA and the canonical axes of the CVA. 


\section{RESULTS}

The CVA provided a visual display of the morphospace considering the two groups of $L$. vannamei and L. schmitti, with component 1 representing 92.31\% of the total variance (Fig. 2). The majority variation of shape is interspecific, although by the second axis, even if in lesser proportion, it is possible to identify that $L$. vannamei possesses a particular morphological variation distinct between cultured and natural specimens.

The results of the CVA are reaffirmed by the DFA, which confirms both the statistical difference of shape between $L$. schmitti and $L$. vannamei, and the statistical similarity in shape between the groups of L. vannamei from the natural environment and cultivated in shrimp farms. Among the species, discriminant function analysis determined statistical difference between L. schmitti and L. vannamei (procrustes distance $=0.0293 ; \mathrm{P}<0.01)$ (Table II, Fig. 3a). For this relationship, we obtained $96.42 \%$ of correct signaling of the cross-validation matrix for L. schmitti and $100 \%$ for L. vannamei. In the evaluation regarding the groups of origin, the DFA showed statistical difference in the two interspecific relationships, revealing greater similarity when both species are of the natural environment (distance of procrustes $=0.0273 ; \mathrm{P}$ $=0.037$ ) (Table II, Fig. 3b), and lower similarity when the non-native species is from shrimp farms (distance from procrustes $=0.0308$; $\mathrm{P}<$ 0.01) (Table II, Fig. 3c). The cross-validation matrix indicated higher percentages of correct classification when cultured L. vannamei individuals were compared, $71.42 \%$ for $L$.

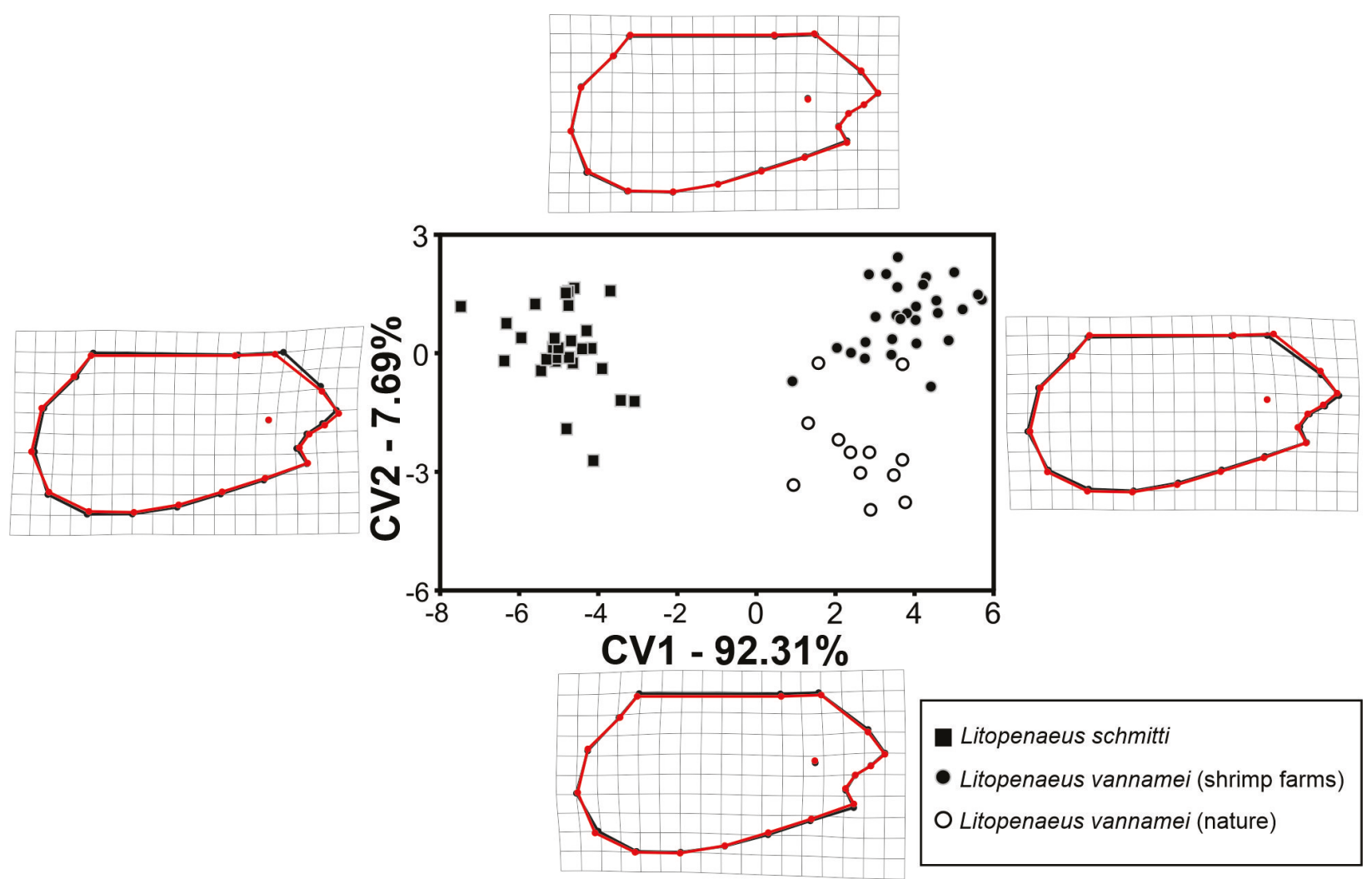

Figure 2. Canonical variable analysis of the 'species' (Litopenaeus schmitti and Litopenaeus vannamei) vs. 'origin' (nature and shrimp farms) factors as grouping factors and the deformation grids and shape wireframes for each investigated componente. Red = L. schmitti; Black = L.s vannamei. 
schmitti, and $66.66 \%$ for L. vannamei from the natural environment, and $96.42 \%$ for L. schmitti and $92.82 \%$ for $L$. vannamei from shrimp farms. There was no statistical difference between L. vannamei (procrustes distance $=0.0112 ; \mathrm{P}=$ 0.206).

The two species of shrimp differ concerning the cephalothorax geometry, mainly in the rostrum stretch and relative position of the first rostral tooth to the hepatic spine. The cephalothorax shape of L. schmitti has a more stretched, dorsoventrally, and more compact profile (lower antero-posteral stretch), with points that form the base of the rostral spine closer (Landmark 6 and 7) (Fig. 3a). Additionally, the anatomical landmark representing the first rostral tooth (Landmark 7 ) revealed a vector displacement to the opposite side of the tip position of the hepatic spine (Fig. 4a). In contrast, L. vannamei presented a wider geometry and less stretched dorsoventrally, with the points of the base of the rostrum more distant from each other (Fig. 3a). Moreover, the point that represents the first rostral tooth showed an opposite displacement in relation to the anterior species, tending to a parallel position the tip of the hepatic spine (Fig. 4b).

\section{DISCUSSION}

Studies on the shape of cephalothorax in shrimps are recent and mainly deal with geometric morphometrics as a tool for assessing sexual dimorphism (Accioly et al. 2013, Sganga et al. 2016) or population discrimination (Bissaro et al. 2013, Torres et al. 2014, Zimmerman et al. 2011, Moraes et al. 2020). All previous studies were intra-specific, with no objective to examine the relationship between similar species or congeners. Although interspecific differences in the shape have already been observed in sister species of crustaceans (Giri \& Loy 2008, Riedlecker et al. 2009), the present study is the first to investigate the body shape using geometric morphometrics technique by anatomical landmarks as a tool to aid the taxonomic discrimination among shrimp species.

Among the species used in this study, it was possible to observe a significant geometric variation between the cephalothorax of the native species $L$. schmitti and the non-native L. vannamei. Phylogenetic studies on shrimp of the genus Penaeus sensu lato Fabricius, 1798 argue that a single lineage of species of Penaeus s. l. colonized the Americas, recently, from the Pacific Western, and then they diverged in the lineages of Farfantepenaeus and Litopenaeus,

Table II. Statistical results for comparison of shape variation between grouping factors 'species' ( $L$. schmitti and $L$. vannamei) and 'origin' (nature and shrimp farms).

\begin{tabular}{|c|c|c|c|c|c|}
\hline DFA & $\mathbf{T}^{\mathbf{2}}$ & $\mathbf{T}^{2} \mathbf{P}$ & $\mathbf{D}^{\mathbf{2}}$ & Proc Dist & $\mathbf{P}^{* *}$ \\
\hline L. schmitti X L. vannamei & 1090.61 & $<0.01$ & 8.13 & 0.0293 & $<0,01$ \\
\hline L. schmitti (nature) X L. vannamei (nature) & 1322.15 & 0.03 & 12.54 & 0.0273 & $<0,01$ \\
\hline L. schmitti (nature) X L. vannamei (shrimp farms) & 1227.37 & $<0.01$ & 9.36 & 0.0308 & $<0,01$ \\
\hline L. vannamei (nature) X L. vannamei (shrimp farms) & 545.47 & 0.20 & 8.05 & 0.0112 & 0,31 \\
\hline
\end{tabular}

DFA, Discriminant Function Analysis; $\mathrm{T}^{2}$, Hotteling $\mathrm{t}$ test; $\mathrm{D}^{2}$, Mahalanobis distance; Proc Dist, Procrustes distance. ** Significance value for the permeation test of the distance of procrustes between the groups. 
thus distributing to both sides of the Americas (Lavery et al. 2004). After the complete closure of the Isthmus of Panama, vicariant speciation occurred, leading to the different lineages currently found on each side of the Americas (Lavery et al. 2004, Maggioni et al. 2001). Though L. schmitti and L. vannamei present significant genetic divergences that are characterized as distinct species, they still share similarities in the general appearance (characteristic typical to the entire Penaeus s. l. group). Despite this similarity, differences in food, food conversion, growth rate, use of microhabitat, competition, and environmental conditions can be reflected in small differences in the shape of organisms
(Peres-Neto 1995). For example, the muscle growth pattern in shrimps is directly related to the type of diet and chemical composition (Mondal et al. 2014). Similarly, the conditions and habitat use directly influence the development of organisms and result in morphological and physiological changes (Bissaro et al. 2013, Castilho et al. 2007). These observations are frequent in species with a broad geographic distribution (Bissaro et al. 2013). Since L. vannamei and L. schmitti evolved in distinct marine ecoregions (sensu Spalding et al. 2007), the pattern observed in this study suggests that cephalothorax, and/ or organs and internal musculature related to this structure, in L. schmitti was subjected to a) Litopenaeus schmitti vs Litopenaeus vannamei
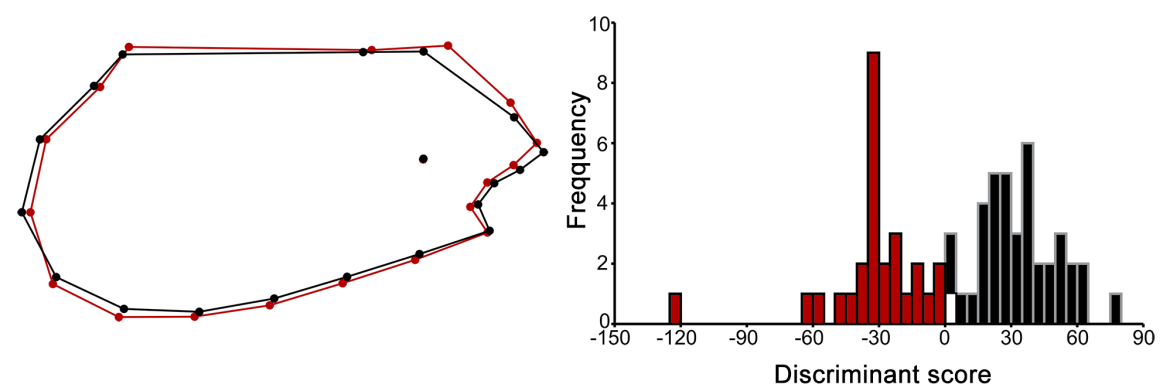

b) Litopenaeus schmitti vs Litopenaeus vannamei (nature)
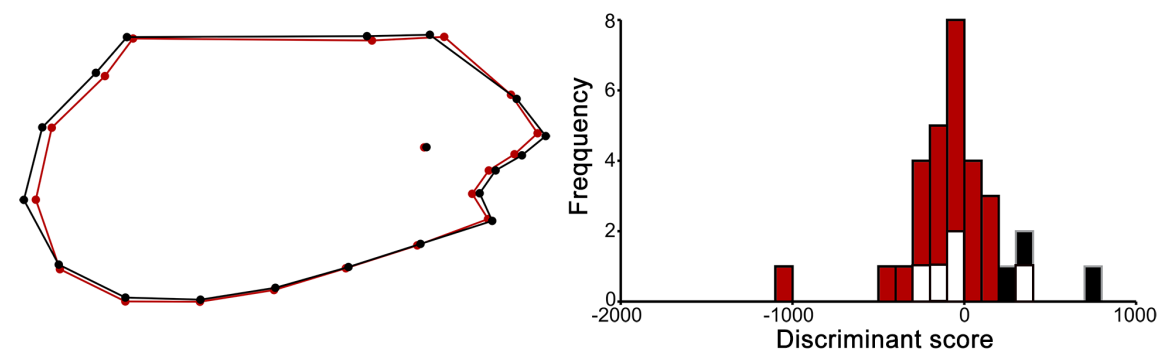

c) Litopenaeus schmitti vs Litopenaeus vannamei (shrimp farm)
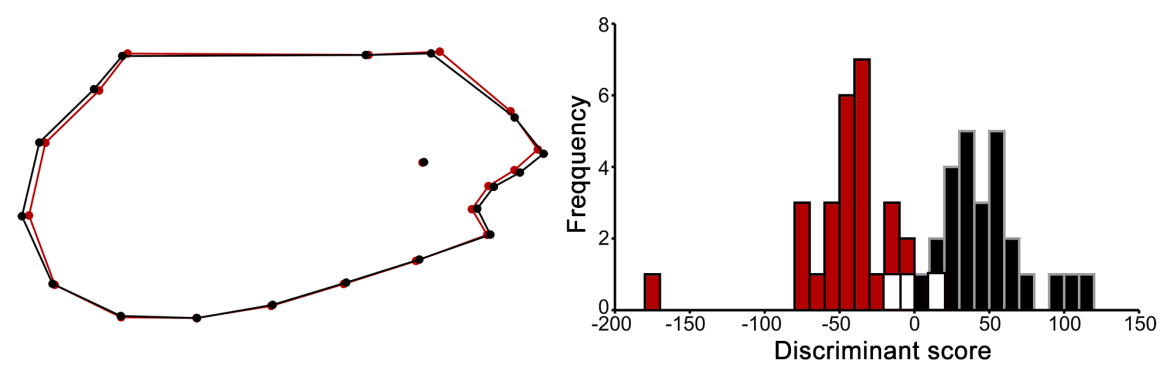

Figure 3. Comparison wireframe of cephalothorax shape and frequencies of discriminant function scores. Deviations between the corresponding anatomical landmarks between the analysis groups represent the vector displacement. Red $=$ Litopenaeus schmitti; Black = Litopenaeus vannamei; White = frequency overlap. 
distinct selective pressures from those that affected the evolutionary history of L. vannamei. Although this observation seems evident from the evolutionary point of view, it is not valid for all structures and all Crustacea taxa. Rosenberg (2002), for example, evaluated the shape of the largest chelipeds among species of the genus Uca and concluded what they called "unexpected result" that, although specific clades appear to present shape of distinct chelipeds, the analysis indicated a phylogenetic convergence (phylogenetic agglomeration) of the shape of the chelipeds in the whole genus.

For the adult male shrimps of the present study, our result evidenced a characteristic that can help in the macroscopic distinction between these two species of Penaeidae: the position of the base of the first rostral tooth, in relation to the tip of the hepatic spine. In L.schmitti, the first tooth of the rostrum develops in a position more anterior than in L. vannamei,
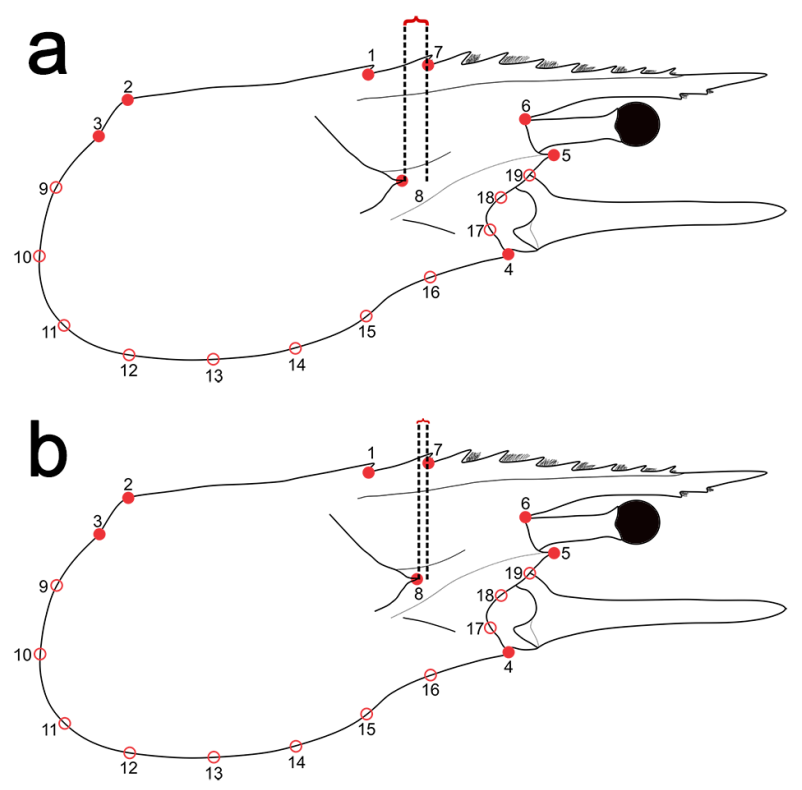

Figure 4. Cephalothorax right profile of Litopenaeus illustrating the difference in the position of the base of the first rostral tooth in relation to the tip of the hepatic spine between Litopenaeus schmitti (a) and Litopenaeus vannamei (b). never aligning the tip of the hepatic spine. In $L$. vannamei, the first rostral tooth develops closer or in the same vertical plane in which the tip of the hepatic spine is visualized (Fig. 4). This shape characteristic, together with the observation of the structures of the petasma (Pérez-Farfante 1969, A.B. Moraes et al., unpublished data), can ensure field identification at the species level for these congeners.

Studies such as Bissaro et al. (2013), Torres et al. (2014) and Zimmerman et al. (2011) demonstrated that the physical structure of the environment, the flow of water, magnitude of the currents, and type of sediment could directly influence the shape of the cephalothorax of shrimps. It occurs because this structure is directly related to many functions (e.g., nutrition, locomotion, and perception), causing it to have different responses according to different environments (Zimmerman et al. 2011). In the case of $L$. vannamei, shrimp farms environments have very different physical and hydrological factors than what is found in the natural environment, which can cause differentiations in shape between the cultivated and natural environment groups. Although the results obtained do not indicate a statistically significant difference in shape $(P>0.05)$, it was possible to observe a slight distinction of shape in terms of prawn origin. This small dissimilarity between the origin of L. vannamei becomes more apparent when the non-native species is compared with the native L. schmitti. However, investigations with a new configuration of anatomical landmarks, including more detail in the capture of the carapace can help corroborate our current proposition.

Juvenile individuals of Litopenaeus, in general, have similar cephalothorax morphology (Pérez-Farfante 1969). Therefore, species of the same genus that co-occur can make it difficult to identify specimens at the species level. Our 
results show that congenital adults have a higher similarity of cephalothorax when L. vannamei is of natural capture. Until now, the characters that remain most reliable for the identification of juveniles of the genus are the structure of the petasma and the thelycum (Pérez-Farfante 1970, A.B. Moraes et al., unpublished data). We suggest that additional investigations using geometric morphometrics by anatomical landmarks can reveal whether the characteristics observed here for adult males can also be used to identify females and juveniles of both species. Additionally, linear measurements can be applied to quantify the difference in the position of the hepatic spine among the species. The authors also suggested the need for a comparative study between wild (from their geographic area of origin) and cultivated L. vannamei. This comparison would aim to evaluate whether genetic erosion resulting from consanguinity and low genotypic diversity, which occurs in cultivated animals (Doyle 2016), affects the shape of body structures and to quantify the extent of these changes.

In general, the study demonstrated the differences in shape, which can be the result of evolutionary influences. Since the species are related to biological invasions, this contribution can reduce the probability of identification errors that would lead to errors in the database on the history of invasion. Moreover, the description of the variation is also the first step in understanding the evolution of a complex morphological structure subjected to distinct evolutionary histories. The next step is to study how these variations are specifically related to the differences in the function of structures associated with cephalothorax.

\section{Acknowledgments}

This study was financed in part by the Coordenação de Aperfeiçoamento de Pessoal de Nivel Superior Brazil (CAPES) - Finance Code 001. The authors are thankful to the members of LABEEC for support in the laboratory analysis; to the Programa de Pós-Graduação em Sistemática e Evolução and Programa de PósGraduação em Ecologia (UFRN) for supporting the project; to the Conselho Nacional de Desenvolvimento Científico e Tecnológico/Ministério da Pesca (CNPq/MPA 407046/2012-7) for supporting the project that made the biological sampling possible, and to the Instituto Chico Mendes - Ministério do Meio Ambiente (ICMBio/MMA) for the sampling license permission (SISBIO/ICMBIO 28314-1).

\section{REFERENCES}

ACCIOLY IV, LIMA-FILHO PA, SANTOS TL, BARBOSA ACA, CAMPOS LBS, SOUZA JV, ARAÚJO WC \& MOLINA WF. 2013. Sexual dimorphism in Litopenaeus vannamei (Decapoda) identified by geometric morphometrics. Pan-Am J Aquat Sci 8: 276-281.

ADAMS DC, ROHLF FJ \& SLICE DE. 2013. A field comes of age: geometric morphometrics in the 21st century. Hystrix 24: 7-14.

ADAMS DC, ROHLF FJE \& SLICE DE. 2004. Geometric morphometrics: ten years of progress following the "revolution." Ital J Zool 71: 5-16.

ALENCAR CERD, LIMA-FILHO PA, MOLINA WF \& FREIRE FAM. 2014. Sexual shape dimorphism of the mangrove crab Ucides cordatus (Linnaeus, 1763) (Decapoda, Ucididae) accessed through geometric morphometric. Sci World J 2014: 1-8.

BARBIERI E \& MELO GAS. 2006. Biodiversidade: ocorrência da espécie exótica Litopenaeus vannamei (Boone, 1931) no complexo estuarino-lagunar de Cananéia-IguapeItha Comprida. Mundo Saúde 30: 654-659.

BISSARO FG, GOMES-JR JL \& DI BENEDITTO APM. 2013. Morphometric variation in the shape of the cephalothorax of shrimp Xiphopenaeus kroyeri on the east coast of Brazil. J Mar Biol Assoc UK 93: 683-691.

BOOKSTEIN FL. 1982. Foundations of Morphometrics. Annu Rev Ecol Evol Syst 13: 451-470.

BRIGGS M, FUNGE-SMITH S, SUBASINGHE R \& PHILLIPS M. 2004. Introductions and movement of Penaeus vannamei and Penaeus stylirostris into Asia and the Pacific. Bangkok: Food and Agriculture Organization of the United Nations, 
Regional Office for Asia and the Pacific, RAP Publ, Bangkok, TH, $92 \mathrm{p}$.

CARDINI A. 2016. Lost in the Other Half: Improving Accuracy in Geometric Morphometric Analyses of One Side of Bilaterally Symmetric Structures. Syst Biol 65: 1096-1106.

CASTILHO AL, GAVIO MA, COSTA RC, BOSCHI EE, BAUER RT \& FRANSOZO A. 2007. Latitudinal variation in population structure and reproductive pattern of the endemic South American shrimp Artemesia longinaris (Decapoda: Penaeoidea). J Crustacean Biol 27: 548-552.

DRAKE AG \& KLINGENBERG CP. The pace of morphological change: historical transformation of skull shape in St Bernard dogs. Proc R Soc B 275: 71-76.

FREITAS PD, JESUS CM \& GALETTI JR PM. 2007. Isolation and characterization of new microsatellite loci in the Pacific white shrimp Litopenaeus vannamei and cross-species amplification in other penaeid species. Molecular Ecology Notes 7: 324-326.

COCK AG. 1966. Genetical aspects of metrical growth and form in animals. Q Rev Biol 41: 131-190.

DALL W, HILL BJ, ROTHLISBERG PC \& STAPLES DJ. 1990. The biology of the Penaeidae. In: Blaxter JHS \& Southward AJ (Eds). Advances in Marine Biology. San Diego: Academic press 27: 1-489.

DOYLE RW. 2016. Inbreeding and disease in tropical shrimp aquaculture: a reappraisal and caution. Aquac Res 47: 21-35.

DRYDEN IL \& MARDIA KV. 1998. Statistical shape analysis. Wiley, Chichester, England.

GIRI F \& LOY A. 2008. Size and shape variation of two freshwater crabs in argentinean Patagonia: the influence of sexual dimorphism, habitat, and species interactions. J Crustacean Biol 28: 37-45.

GUNZ P \& MITTEROECKER P. 2013. Semilandmarks: a method for quantifying curves and surfaces. Hystrix 24: 103-109.

HELMS BS, VAUGHT RC, SUCIU SK \& SANTOS SR. 2015. Cryptic diversity within two endemic crayfish species of the Southeastern US revealed by molecular genetics and geometric morphometrics. Hydrobiologia 755: 283.

KLINGENBERG CP. 2011. MORPHOJ: an integrated software package for geometric morphometrics. Mol Ecol Resour 11: 353-357.

KLINGENBERG CP. 2013. Visualizations in geometric morphometrics: how to read and how to make graphs showing shape changes. Hystrix 24: 15-24.
KLINGENBERG CP \& MONTEIRO LR. 2005. Distances and directions in multidimensional shape spaces: implications for morphometric applications. Syst Biol 54: 678-688.

LAVERY S, CHAN TY, TAM YK \& CHU KH. 2004. Phylogenetic relationships and evolutionary history of the shrimp genus Penaeus s.l. derived from mitochondrial DNA. Mol Phylogenet Evol 31: 39-49.

LOEBMANN D, MAI ACG \& LEE JT. 2010. The invasion of five alien species in the Delta do Parnaíba Environmental Protection Area, Northeastern Brazil. Rev Biol Trop 58: 909-923.

MAGGIONI R, ROGERS AD, MACLEAN N \& D'INCAO F. 2001. Molecular phylogeny of western Atlantic Farfantepenaeus and Litopenaeus shrimp based on mitochondrial 16S partial sequences. Mol Phylogenetics Evol 18: 66-73.

MONDAL K, BHATTACHARYYA SB, MITRA A \& DAS M. 2014. Impact of different diet categories on muscle growth dynamics of freshwater prawn, Macrobrachium rosenbergii. Int J Pharma Bio Sci 4: 01-07.

MORAES SASN, ALENCAR CERD, LIMA SMQ \& FREIRE FAM. 2020. Shape variation of the prawn Macrobrachium jelskii (Palaemonidae: Decapoda) in the Neotropical semiarid drainages: an intra- and inter-basin investigation. Mar Freshwater Res 72(1): 84-98.

PERES-NETO PR. 1995. Introdução a análises morfométricas. Oecologia Bras 2: 57-89.

PÉREZ-FARFANTE I. 1969. Western Atlantic shrimps of the genus Penaeus. Fish B-NOAA 67: 462-591.

PÉREZ-FARFANTE I. 1970. Diagnostic characters of juveniles of the shrimps Penaeus aztecus aztecus, P. duorarum duorarum, and P. brasiliensis (Crustacean, Decapoda, Penaeidae). U.S. Del'. Commer. NOAA Special scientific report-Fish 559: 1-26.

PÉREZ-FARFANTE I. 1988. Illustrated Key to Penaeoid Shrimps of Commerce in the Americas. NORA Technical Reports NMFS 64: 1-32.

PÉREZ-FARFANTE I \& KENSLEY B. 1997. Penaeoid and Segestoid Shrimps and Prawns of the World. Keys and diagnoses for the families and genera. Éditions du Muséum national d'Histoire naturalle, Paris, p. 233.

RIEDLECKER EI, ASHTON GV \& RUIZ GM. 2009. Geometric morphometric analysis discriminates native and nonnative species of Caprellidae in western North America. J Mar Biol Assoc UK 89: 535-542. 
ROHLF FJ. 2006. tpsDig version 2.1.0. Ecology and Evolution, SUNY at Stony Brook. http:// life.bio.sunysb.edu/morph/. Accessed 02 February 2016.

ROHLF FJ \& MARCUS LF. 1993. A revolution in morphometrics. Trends Ecol Evol 8: 129-132.

ROHLF FJ \& SLICE DE. 1990. Extensions of the procrustes method for the optimal superimposition of landmarks. Syst Zool 39: 40-59.

ROSENBERG MS. 2002. Fiddler crab claw shape variation: a geometric morphometric analysis across the genus Uca (Crustacea: Brachyura: Ocypodidae). Biol J Linn Soc Lond 75: 147-162.

SANTOS MCF \& COELHO PA. 2002. Espécies exóticas de camarões marinhos (Penaeus monodom Fabricius, 1798 e Litopenaeus vannamei (Boone, 1931)) nos ambientes estuarino e marinho do nordeste do Brasil. Bol Téc Cient CEPENE 10: 209-222.

SGANGA DE, PIANA LRF \& GRECO LSL. 2016. Sexual dimorphism in a freshwater atyid shrimp (Decapoda: Caridea) with direct development: a geometric morphometrics approach. Zootaxa 4196: 120-128.

SPALDING MD ET AL. 2007. Marine ecoregions of the world: a bioregionalization of coastal and shelf areas. Bioscience 57: 573-583.

TAVARES M. 2011. Alien decapod crustaceans in the Southwestern Atlantic Ocean. In: Galil BS, Clark PF \& Carlton JT (Eds), In the Wrong Place - Alien Marine Crustaceans: Distribution, Biology and Impacts Invading Nature, Dordrecht: Springer Series in Invasion Ecology, Dordrecht, NL, p. 251-268.

TORRES MV, PABLO FG \& COLLINS A. 2014. Geometric morphometric analysis of the freshwater prawn Macrobrachium borellii (Decapoda: Palaemonidae) at a microgeographical scale in a floodplain system. Ecol Res 29: 959-968.

VISCOSI V \& CARDINI A. 2011. Leaf morphology, taxonomy and geometric morphometrics: a simplified protocol for beginners. PLOS ONE 6: e25630.

ZIMMERMANN G, BOSC P, VALADE P, CORNETTE E, AMÉZIANE N \& DEBAT V. 2011. Geometric morphometrics of carapace of Macrobrachium australe (Crustacea: Palaemonidae) from Reunion Island. Acta Zool 93: 492-500.

\section{How to cite}

MORAES AL, DE MORAES DCS, ALENCAR CERD \& FREIRE FAM. 2021. Native and non-native species of Litopenaeus Pérez-Farfante, 1969 (Crustacea: Penaeidae) from the East Atlantic: Geometric morphometrics as a tool for taxonomic discrimination. An Acad Bras Cienc 93: e20200107. DOI 10.1590/0001-3765202120200107.

Manuscript received on January 22, 2020;

accepted for publication on October 25, 2020

\section{ALEX B. DE MORAES ${ }^{1}$}

https://orcid.org/0000-0003-3407-4641

DANIELE C.S. DE MORAES ${ }^{1}$

https://orcid.org/0000-0003-0608-9459

CARLOS EDUARDO R.D. ALENCAR ${ }^{1,2}$

https://orcid.org/0000-0003-4231-4326

\section{FÚLVIO A.M. FREIRE ${ }^{1}$}

https://orcid.org/0000-0003-1580-0222

${ }^{1}$ Universidade Federal do Rio Grande do Norte, Departamento de Botânica e Zoologia, Laboratório de Biologia, Ecologia e Evolução de Crustáceos (LABEEC), Campus Universitário Lagoa Nova, Caixa Postal 1524, 59072-970 Natal, RN, Brazil

${ }^{2}$ Universidade Regional do Cariri, Departamento de Ciências Biológicas, Laboratório de Crustáceos do Semiárido (LACRUSE), Rua Cel. Antônio Luiz, 1161, 63105-000 Crato, CE, Brazil

Correspondence to: Alex Barbosa de Moraes, Fúlvio Aurélio de Morais Freire

E-mails: alexbarbosa@outlook.com/fulvio@cb.ufrn.br

\section{Author contributions}

Alex Barbosa: Conceptualization, Methodology, Investigation, Formal Analysis, Data Curation, Writing - Original Draft, Visualization. Daniele Cosme: Methodology, Investigation, Writing - Original Draft, Writing - Review \& Editing. Carlos Eduardo Alencar: Conceptualization, Methodology, Validation, Visualization, Writing - Review \& Editing. Fúlvio Aurélio Freire: Conceptualization, Supervision, Project Administration, Funding Acquisition, Writing - Review \& Editing.

(cc) BY 